\title{
Tinjauan Kasus Kegawatdaruratan Maternal Dan Neonatal
}

\author{
Sefita Aryuti Nirmala ${ }^{1}$, R. Tina Dewi Judistiani ${ }^{2}$, Sri Astuti ${ }^{3}$, Wulan Tanti Aprianti ${ }^{4}$ \\ 1,3 Departemen Ilmu Kesehatan Masyarakat Fakultas Kedokteran Universitas Padjadjaran, Indonesia \\ ${ }^{2}$ Departemen Epidemiologi dan Biostatiska Fakultas Kedokteran Universitas Padjadjaran, Indonesia \\ ${ }^{4}$ Program Studi Diploma IV Kebidanan Fakultas Kedokteran Universitas Padjadjaran, Indonesia
}

\begin{tabular}{l}
\hline ARTICLE INFORMATION \\
\hline Article Trace \\
Submission: April 03, 2018 \\
Final Revision: July 10, 2018 \\
Available online: October 20, 2018 \\
\hline
\end{tabular}

Kata Kunci:

Kasus Rujukan, Kegawatdaruratan maternal, Kegawatdaruratan neonatal

Key Word :

Urgency, maternal mortality, neonatal mortality,

Contact:

sefitaaryuti@gmail.com

\begin{abstract}
A B S T R A C T
Terdapatnya Angka Kematian Ibu (AKI) dan Angka Kematian Neonatal (AKN) di Kabupaten Sumedang disebabkan oleh kegawatdaruratan Maternal dan Neonatal. Kegawatdaruratan Maternal merupakan kejadian berbahaya yang dapat mengancam jiwa akibat dari masalah kehamilan, persalinan, atau nifas. Kegawatdaruratan Neonatal merupakan kejadian yang mengancam jiwa bayi baru lahir usia 0-28 hari. Terdapat jumlah kematian ibu bersalin 1 orang di wilayah kerja Puskesmas Tanjungsari dan kematian neonatal terdapat 8 orang. Tujuan dari penelitian ini adalah untuk mengetahui kasus kegawatdaruratan maternal dan neonatal di Puskesmas PONED Tanjungsari tahun 2015. Penelitian ini menggunakan metode penelitian deskriptif dan pendekatan potong lintang. Data diperoleh secara retrospektif dari rekam medik pasien yang mengalami kegawatdaruratan maternal dan neonatal di Puskesmas PONED Tanjungsari Kabupaten Sumedang pada tahun 2015. Kasus kegawatdaruratan Maternal yang sering terjadi di Puskesmas Tanjungsari adalah Ketuban Pecah Dini dengan jumlah 28 kasus (37,8\%). Pada tahun 2015 di Puskesmas PONED Tanjungsari tidak tercatat dan tidak terdapat kegawatdaruratan Neonatal. Karakteristik Umur maternal yang mengalami kegawatdaruratan terbanyak dari rentan usia 20-35 tahun dengan jumlah kasus 51 kasus $(68,9 \%)$. Paritas 2-3 dengan jumlah kasus 37 (50\%). Luaran kasus rujukan dengan kondisi sehat 72 kasus $(97,3 \%)$ dan mengalami komplikasi 2 kasus $(2,7 \%)$. Kasus kegawatdaruratan yang terjadi di Puskesmas Tanjungsari terbanyak adalah Ketuban Pecah Dini dengan karakteristik umur maternal yang sering mengalami kegawatdaruratan rentan umur 20-35 tahun dan paritas 2-3, Puskesmas Tanjungsari telah melakukan prosedur klinik sebelum merujuk dengan melakukan stabilisasi pasien sebelum dirujuk dan merujuk pasien kegawatdaruratan pada rumah sakit PONEK terdekat dengan luaran kasus rujukan keadaan maternal sebagian besar sehat sampai pada rumah sakit PONEK.
\end{abstract}

\begin{abstract}
A B S T R A C T
The maternal mortality (AKI) and the neonatal mortality (AKN) in Kabupaten Sumedang is caused by the maternal urgency and neonatal. The maternal urgency is a dangerous phenomena that can be a lifethreatening caused by the problems of pregnancy, labor, and postpartum. It is the phenomena that threatens the life of newborn babies in the range of 0-28 days old. This study aimed to investigate the maternal and neonatal urgency in Puskesmas PONED Tanjungsari in 2015. Descriptive method with cross sectional approachment was used in this study. The data was retrospectively gained from the medical record of the patients that experienced maternal and neonatal urgency in Puskesmas PONED Tanjungsari Kabupaten Sumedang in 2015. The cases of maternal urgency that frequently happened in Puskesmas Tanjungsari was premature rupture of membranes that reached 28 cases or $37,8 \%$. Meanwhile, in 2015 , there was no neonatal urgency happened and recorded in Puskesmas PONED Tanjungsari. The characteristics of maternal age that experienced the maternal urgency was about 20-35 years ord with 51 cases happened or $68,9 \%$. The number of live birth in range of 2-3 reached 37 cases or $50 \%$. The referal cases with a healthy condition reached 72 cases or $97,3 \%$ and for them who got complicated cases reached 2 cases or $2,7 \%$. The cases of maternal and neonatal urgency that happened in Puskesmas Tanjungsari mostly caused by the
\end{abstract}


premature rupture of membranes with the characteristics of maternal age about 20-35 years old and the number of live birth in range of 2-3. Puskesmas Tanjungsari has followed the clinic procedure before referring the patients to the nearest PONEK hospital by doing stabilization to the patients. Moreover, the condition of the patients reffered to the nearest PONEK hospital were mostly in a good and health condition.

\section{PENDAHULUAN}

Kematian ibu menurut definisi WHO adalah kematian selama kehamilan atau dalam periode 42 hari setelah berakhirnya kehamilan, akibat semua sebab yang terkait dengan atau diperberat oleh kehamilan atau penanganannya, tetapi bukan disebabakan oleh kecelakaan atau cedera. Di Indonesia Jumlah angka kematian ibu menurut Survey Demografi dan Kesehatan Indonesia (SDKI) tahun 2012 adalah 359 per 100.000 kelahiran hidup. Menurut Direktorat Kesehatan Ibu tahun 2013 kematian ibu 30,3\% disebabkan oleh perdarahan, penyebab lainnya adalah hipertensi, infeksi, dan lain-lain.

Jumlah Angka Kematian Neonatal adalah 19 per 1000 kelahiran hidup. penyebab kematian neonatal pada kelompok umur 0-6 hari menurut (Riskesdas, 2007) adalah gangguan kelainan pernafasan $35,9 \%$; prematuritas $32,4 \%$; sepsis $12 \%$; hipotermi $6,3 \%$; kelainan perdarahan dan kuning $5,6 \%$; postmatur $2,8 \%$; malformasi kongenital 1,4\%, sedangkan pada usia 7-28 hari penyebab kematian terbesar kerena sepsis (20,5\%); malformasi kongenital (18,1\%); pneumonia $(15,4 \%)$; sindrom gawat pernafasan $(12,8 \%)$ dan prematuritas (12,8\%).Jumlah kematian Neonatal di Wilayah kerja Puskesmas Tanjungsari tahun 2015 terdapat 8 orang ( UPTD Puskesmas Tanjungsari, 2015)

Kegawatdaruratan maternal dan neonatal dapat ditangani dari mulai pelayanan dasar sampai pelayanan yang lebih komprehensif. Pelayanan Obstetri Neonatal Emergensi Dasar (PONED) adalah puskesmas rawat inap yang mampu menyelenggarakan pelayanan obstetri dan neonatal emergensi atau komplikasi. Jumlah puskesmas mampu PONED di Kabupaten Sumedang berjumlah 11, puskesmas Tanjungsari termasuk puskesmas mampu PONED (BppdK Sumedang, 2014) . Pada kondisi Puskesmas yang difungsikan sebagai pusat rujukan-antara tidak mampu memberi layanan rujukan medis pada kasus obstetri dan neonatal (PONED), pasien harus secepatnya dirujuk ke RS rujukan (PONEK/RSSIB) yang dilakukan stabilisasi terlebih dahulu oleh Puskesmas PONED. (Kemenkes RI, 2013).

Rumah sakit PONEK 24 jam adalah Rumah Sakit yang menyelenggarakan pelayanan kegawatdaruratan maternal dan neonatal secara komprehensif dan terintegrasi 24 jam sehari, 7 hari dalam seminggu. RS mampu PONEK 24 jam memiliki tenaga dengan kemampuan serta sarana dan prasarana penunjang yang memadai untuk memberikan pelayanan pertolongan kegawatdaruatan obstetrik dan neonatal dasar maupun komprehensif untuk secara langsung terhadap ibu hamil,ibu bersalin dan ibu nifas baik yang datang sendiri atau atas rujukan kader atau masyarakat, Bidan di desa, Puskesmas dan puskesmas mampu PONED.( Kemenkes RI, 2013)

RS rujukan PONEK harus dapat dijangkau oleh masyarakat dalam waktu kurang dari 1 jam, agar dapat memberikan tindakan darurat sesuai standar (Kemenkes RI, 2012).Puskesmas Tanjungsari adalah wilayah cakupan RS PONEK Sumedang.

Berdasarkan penjelasan tersebut, peneliti tertarik untuk meneliti kasus rujukan kegawatdaruratan maternal dan neonatal di Puskesmas PONED Tanjungsati Kabupaten Sumedang tahun 2015, dengan tujuan untuk mengetahui kasus kegawatdaruratan maternal dan neonatal di Puskesmas PONED Tanjungsari tahun 2015, mengetahui karakteristik kasus 
rujukan kegawatdaruratan maternal dan neonatal dan kondisi pasien kegawatdaruratan pada saat dilakukan rujukan ke rumah sakit PONEK

\section{METODE PENELITIAN}

Jenis penelitian ini adalah penelitian kuantitatif dengan menggunakan metode penelitian deskriptif dan pendekatan potong lintang. Data diperoleh secara retrospektif dari rekam medik pasien yang mengalami kegawatdaruratan maternal dan neonatal di Puskesmas PONED Tanjungsari Kabupaten Sumedang pada tahun 2015.

Populasi pada penelitian ini adalah kasus kegawatdaruratan maternal dan neonatal di Puskesmas PONED Tanjungsari Kabupaten Sumedang pada tahun 2015 yaitu 81 kasus Maternal dan 3 kasus neonatal. Pengambilan sampel adalah dengan cara total sampling yaitu seluruh kasus kegawatdaruratan maternal dan neonatal di Puskesmas PONED Tanjungsari sejak Januari sampai dengan Desember 2015. Kriteria inklusi pada penelitian ini adalah data rekam medik mengenai kasus kegawatdaruratan maternal dan neonatal di Puskesmas PONED Kecamatan Jatinangor pada tahun 2015. Kriteria Ekslusi adalah data rekam medik mengenai kasus kegawatdaruratan maternal dan neonatal yang tidak lengkap.

Setelah pengumpulan data dilakukan pengelolaan data secara manual. Dari seluruh data yang terkumpul dilakukan penjumlahan masing-masing variabel yang diteliti kemudian dibuat persentasenya. Analisa data menggunakan analisa univariat yang dilakukan secara deskriptif dengan perhitungannya statistik sederhana berupa persentase.

Penelitian ini menggunakan izin etik melalui Komite Etik Penelitian Kesehatan Fakultas Kedokteran Universitas Padjadjaran

\section{HASIL DAN PEMBAHASAN}

Berdasarkan data pada tabel 1 didapatkan bahwa Kasus Kegawatdaruratan yang banyak terjadi di Puskesmas PONED Tanjungsari pada tahun 2015 adalah kasus ketuban pecah dini dengan jumlah 28 kasus (34,6\%).

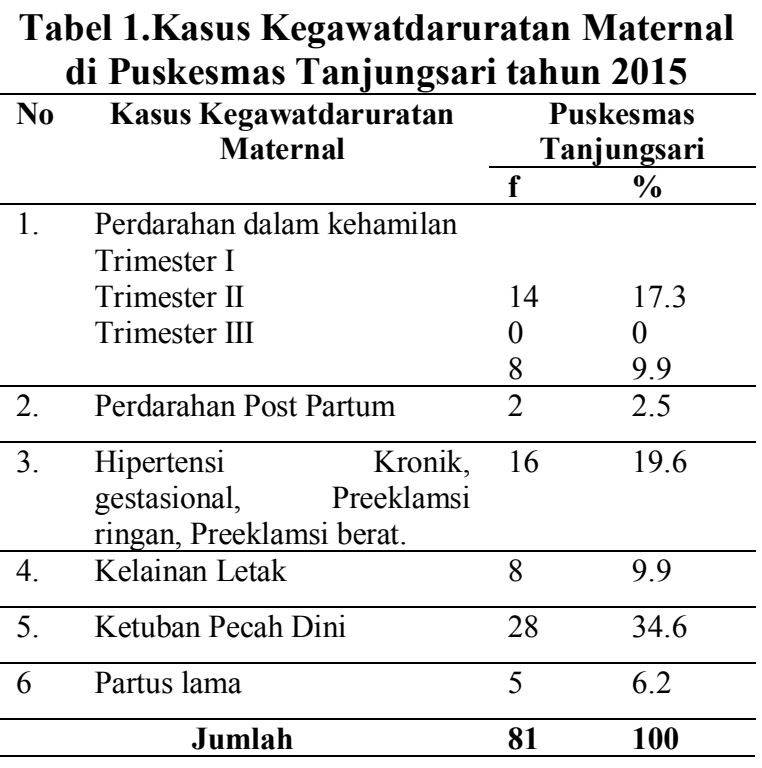

Tabel 2. Karakteristik Umur Kasus Kegawatdaruratan Maternal di Puskesmas Tanjungsari Tahun 2015

\begin{tabular}{ccc}
\hline $\begin{array}{c}\text { Karakteristik Umur } \\
\text { Maternal }\end{array}$ & f & $\%$ \\
\hline$<20$ Tahun & 7 & $\mathbf{8 , 6}$ \\
\hline 20-35 Tahun & 57 & $\mathbf{7 0 , 4}$ \\
\hline$>35$ Tahun & 17 & $\mathbf{2 1 , 0}$ \\
\hline jumlah & $\mathbf{8 1}$ & $\mathbf{1 0 0}$ \\
\hline
\end{tabular}

Pada tabel 2 menunjukan bahwa karakteristik umur maternal yang mengalami kegawatdaruratan banyak terjadi pada kelompok umur 20-35 tahun sebanyak 57 kasus (70,4\%)

Tabel 3. Karakteristik Paritas Kasus Kegawatdaruratan Maternal di Puskesmas Tanjungsari Tahun 2015

\begin{tabular}{lccc}
\hline No & $\begin{array}{c}\text { Karakteristik Paritas } \\
\text { Maternal }\end{array}$ & $\mathbf{f}$ & $\mathbf{\%}$ \\
\hline 1 & $0-1$ & 31 & 38,3 \\
\hline 2 & $2-3$ & 38 & 46,9 \\
\hline 3 & $>3$ & 12 & 14.8 \\
\hline & Jumlah & $\mathbf{8 1}$ & $\mathbf{1 0 0}$
\end{tabular}

Pada Tabel didapatkan bahwa sebagian besar maternal yang mengalami kegawatdaruratan adalah dengan paritas 2-3 dengan jumlah kasus $38(46,9)$. 
Tabel 4. Luaran Kasus Rujukan Kegawatdaruratan maternal di Puskesmas Tanjungsari Tahun 2015

\begin{tabular}{ccc}
\hline $\begin{array}{c}\text { Luaran Kasus } \\
\text { Rujukan } \\
\text { Maternal }\end{array}$ & $\mathbf{f}$ & $\mathbf{\%}$ \\
\hline Sehat & 72 & 97,3 \\
\hline Komplikasi & 2 & 2,7 \\
\hline Kematian & 0 & 0 \\
\hline Jumlah & 74 & 100 \\
\hline
\end{tabular}

Tabel 4 menunjukan bahwa Luaran kasus rujukan Puskesmas PONED Tanjungsari sampai pada RS PONEK yang dituju adalah sebagian besar maternal mempunyai kondisi yang sehat yaitu dengan jumlah 72 kasus $(97,3 \%)$ dan yang mengalami komplikasi 2 kasus kegawatdaruratan $(2,7 \%)$.

\section{Tabel 5. Kasus Neonatal di Puskesmas Tanjungsari Tahun 2015}

\begin{tabular}{lllccc}
\hline \multirow{2}{*}{$\begin{array}{c}\text { N } \\
\text { o }\end{array}$} & $\begin{array}{c}\text { Kasus } \\
\text { Neonatal }\end{array}$ & & Dirujuk & $\begin{array}{c}\text { Tidak } \\
\text { Dirujuk }\end{array}$ & $\begin{array}{c}\text { Menolak } \\
\text { dirujuk }\end{array}$ \\
\cline { 3 - 6 } & & $\mathrm{f}$ & $\mathrm{f}$ & $\mathrm{f}$ & $\mathrm{f}$ \\
\hline 1 & Asfiksia & 0 & 0 & 0 & 0 \\
\hline 2 & Prematur & 1 & 0 & 0 & 1 \\
\hline 3 & Sepsis & 0 & 0 & 0 & 0 \\
\hline 4 & Ikterus & 0 & 0 & 0 & 0 \\
\hline 5 & Diare dan & 0 & 0 & 0 & 0 \\
& Dehidrasi & & & & \\
\hline 6 & BBLR & 3 & 0 & 3 & 0 \\
\hline & Jumlah & $\mathbf{4}$ & $\mathbf{0}$ & $\mathbf{3}$ & $\mathbf{1}$ \\
\hline
\end{tabular}

Berdasarkan data pada tabel diatas di dapatkan 4 kasus neonatal yaitu kelahiran prematur dan BBLR di puskesmas PONED Tanjungsari pada tahun 2015, kelahiran prematur yang terjadi di puskesmas PONED anjungsari dikarenakan pasien menolak untuk dilakukan rujukan pada rumah sakit PONEK.

Tabel 6. Luaran Kasus Neonatal di Puskesmas Tanjungsari tahun 2015

\begin{tabular}{lcccc}
\hline $\mathbf{N}$ & \multirow{2}{*}{$\begin{array}{c}\text { Kasus } \\
\text { Neonatal }\end{array}$} & \multicolumn{3}{c}{ Luaran Kasus } \\
\cline { 3 - 5 } & & Baik & Komplikasi & $\begin{array}{l}\text { Kemati } \\
\text { an }\end{array}$ \\
\hline 1. & $\begin{array}{l}\text { Kelahiran } \\
\text { Prematur }\end{array}$ & 1 & 0 & 0 \\
\hline 2. & BBLR & 3 & 0 & 0 \\
\hline & Jumlah & $\mathbf{4}$ & $\mathbf{0}$ & $\mathbf{0}$
\end{tabular}

Pada kasus kelahiran prematur neonatal mengalami asfiksia ringan dan dilakukan penanganan di puskesmas PONED Tanjungsari dan luarakan kasus tersebut neonatal dalam keadaan baik, dan luaran 3 kasus BBLR yang terjadi di Puskesmas PONED dalam keadaan baik.

Tabel 7. Distribusi Frekuensi

\section{berdasarkan biaya Kasus Rujukan Kegawatdaruratan Maternal}

\begin{tabular}{ccc}
\hline \multirow{2}{*}{$\begin{array}{c}\text { Cara Pembayaran } \\
\text { pada Kasus } \\
\text { Kegawatdaruratan }\end{array}$} & \multicolumn{2}{c}{$\begin{array}{c}\text { Puskesmas } \\
\text { Tanjungsari }\end{array}$} \\
\cline { 2 - 3 } & $\mathrm{f}$ & $\%$ \\
\hline BPJS & 54 & 66.7 \\
\hline Jamkesmas & 9 & 11.1 \\
\hline Umum & 18 & 22.2 \\
\hline Total & 81 & 100 \\
\hline
\end{tabular}

Berdasarkan data pada tabel didapatkan cara pembayaran pada kasus kegawatdaruratan untuk 54 kasus( 66.7\%) menggunakan BPJS, 18 kasus (22.2\%)kegawatdaruratan menggunakan cara pembayaran dengan Umum dan untuk pembayaran menggunakan Jamkesmas terdapat 9 kasus (11.1\%).

Jenis kasus kegawatdaruratan maternal yang terjadi di Puskesmas PONED Tanjungsari pada tahun 2015 terbanyak ditemukan adalah kasus Ketuban Pecah Dini dan kasus yang sering ditemukan lainnya adalah perdarahan pada trimester 1 dalam hal ini abortus inkomplit. Karakteristik umur maternal yang mengalami kegawatdaruratan didominasi oleh kelompok umur maternal 20-35 tahun dengan 57 kasus dan terdapat 17 kasus pada kelompok umur maternal $>$ 35, 7 kasus pada kelompok umur $<20$ tahun.. Umur reproduksi yang tidak sehat dapat menyebabkan resiko yang lebih tinggi untuk terjadinya kasus kegawatdaruratan dimana hal tersebut mengancam mortalitas dan morbiditas tidak hanya pada janin namun juga pada ibu. Selain usia maternal masih terdapatnya kasus kegawatdaruratan yang terjadi pada ibu dengan paritas $>3$, walaupun pada hasil penelitian jumlah paritas yang lebih banyak mengalami kasus kegawatdaruratan maternal adalah pada kelompok paritas 2-3 dengan jumlah kasus 38 . 
Kasus ketuban pecah dini (KPD) adalah kasus terbanyak yang ditemukan di puskesmas PONED Tanjungsari pada tahun 2015 dengan umur maternal yang mengalami KPD didomonasi dengan umur 20-35 dan paritas 2-3. Sejalan dengan teori yang mengatakan bahwa faktor penyebab Ketuban Pecah Dini (KPD) diantaranya adalah : Multiparitas, hidramnion, kelainan letak, Kehamilan ganda dan pendular abdomen (perut gantung) . Multiparitas, hidaramnion, kehamilan ganda dapat menyebabkan Ketuban pecah dini karena terjadi over distensi dinding rahim sedangkan selaput ketuban tipis dan mudah pecah mengakibatkan ketuban pecah dini. Pada penelitian ini tidak ditelusuri penyebab dari Ketuban pecah dini dan hanya menampilkan jumlah kasus dari Ketuban Pecah dini. Pada penelitian (Nurul Huda, 2013) di RS PKU Muhammadiyah Surakata yang menjukan bahwa sebanyak 37 responden (29,6\%) ibu dengan multipara yang mengalami kasus ketuban pecah dini. Bertentangan dengan penelitian tersebut adalah penelitian yang dilakukan oleh (Fatkiyah, N., 2008), dengan hasil tidak ada hubungan yang bermakna antara status paritas dengan kejadian persalinan ketuban pecah dini, yang berarti status paritas bukan sebagai faktor utama penyebab komplikasi persalinan tetapi salah satu faktor predisposisi. Usia gestasi maternal yang mengalami KPD dari jumlah kasus 28 terdapat 26 usia aterm dan 2 usia preterm, usia gestasi preterm yang akan meningkatkan resiko terajadinya komplikasi pada bayi yang dilahirkan seperti BBLR, infeksi.( Manuaba, I., 2004)

Karakteristik Umur maternal yang mengalami kasus kegawatdaruratan di Puskesmas PONED Tanjungsari terbanyak adalah kelompok umur 20-35 tahun hasil tersebut sejalan dengan penelitian yang dilakukan oleh Rizki (Trida, M.,2012) di Rumah sakit PKU Muhammadiyah Yogyakarta pada tahun 2012 bahwa dari 30 responden yang mengalami kasus komplikasi persalinan berjumlah 25 responden memiliki umur berkisar antara 20-35 tahun, dan hasil bivariat yang didapatkan bahwa tidak terdapat hubungan antara umur dan komplikasi persalinan yang terjadi.

Pada hasil pencatatan dan pelaporan serta rekam medik puskesmas PONED Tanjungsari tahun 2015, terdapat 3 kasus bayi yang dilahirkan dengan Berat Badan Lahir Rendah (BBLR) dan 1 bayi dilahirkan dengan usia gestasi preterm. Sedangkan bila merujuk pada profil puskesmas Tanjungsari yang merekap semua data diseluruh desa, terdapat 7 desa yaitu Desa Tanjungsari, Jatisari, Gudang, Margaluyu, Pasigaran, Kadakajaya, Cijambu, yang memiliki kasus komplikasi neonatal berjumlah 155 dan kasus terbanyak adalah Berat badan lahir rendah, peneliti tidak menggali lebih jauh data tentang kegawatdaruratan di desa wilayah kerja Puskesmas Tanjungsari. (UPTD Tanjungsari, 2015)

Hasil penelitian menunjukan bahwa keadaan ibu pada saat datang ke puskesmas PONED dari 81 kasus terdapat 2 kasus yang mengalami komplikasi yaitu pada kasus perdarahan Trimester I dan Trimester III, setelah dilakukan stabilisasi di PONED kondisi ibu baik kemudian dilanjutkan dengan melakukan.

Sesuai dengan alur penanganan di PONED bahwa kasus kegawatdaruratan datang ke PONED dilakukan pemeriksaan fisik dan penunjang terlebih dahulu dan dapat ditentukan diagnosa dan assesment jika kasus tidak dapat ditangani olehh PONED maka harus dirujuk pada rumah sakit PONEK terdekat, kasus yang akan dirujuk harus mendapatkan stabilisasi terlebih dahulu oleh puskesmas PONED kemudian dirujuk pada fasilitas yang lebih komprehensif. (Kemenkes, 2013)

Pada tahun 2015 di puskesmas PONED Tanjungsari terdapat kegawatdaruratan neonatal dengan persalinan premature dan bayi mengalami BBLR, sesuai dengan kewenangan PONED bahwa kasus kegawatdaruratan yang tidak bisa tertangani di PONED harus dirujuk pada rumah sakit PONEK disertai dengan penanganan awal yang dapat dilakukan di 
PONED, sistem rujukan pasien ditentukan juga oleh peran serta keluarga untuk memutuskan bersedia dirujuk atau tidak, kasus kelahiran premature dengan BBLR yang terajadi di PONED tidak dilakukan perujukan ke rumah sakit PONEK karena keputusan keluarga tidak bersedia untuk dirujuk, maka pasien ditangani dengan penanganan awal oleh puskesmas PONED dan pasien pulang yang berarti kasus tidak tertangani dengan selesai.

Menurut teori bahwa kelahiran Premature memiliki risiko tinggi untuk terjadinya asfiksia, Infeksi, Ikterus patologis yang dikarenakan oleh belum sempurnanya organ tubuh, dan bayi premature akan cenderung mempunyai imun tubuh yang kurang yang akan cepat terjadinya infeksi. Dampak tidak tertangani kasus kelahiran premature adalah risiko tinggi untuk terjadinya mortalitas dan morbiditas pada bayi. ( Lawn JE, Davidge R, 2013)

Kasus neonatal yang terjadi selain kelahiran premature adalah kelahiran bayi dengan BBLR yang dapat ditangani oleh puskesmas PONED dan tidak dilakukan rujukan.

Semua kasus Puskesmas PONED Tanjungsari sebagian besar dirujuk ke Rumah Sakit Umum Daerah Sumedang yang membutuhkan waktu tempuh selama 30 menit dari Puskesmas Tanjungsari sesuai dengan pengertian Regionalisasi pelayanan obstetri dan Neonatal adalah suatu sistem pembagian wilayah kerja rumah sakit dengan cakupan area pelayanan yang dapat dijangkau oleh masyarakat dalam waktu kurang dari 1 jam, agar dapat memberikan tindakan darurat sesuai standar. Regionalisasi menjamin agar sistem rujukan kesehatan berjalan secara optimal.

Hasil penelitian ini sejalan dengan penelitian yang dilakukan oleh Rukmini dan Ristini di Puskesmas Tambakrejo dan Tanah Kali Kedinding Kota Surabaya untuk mengetahui pelaksanaan sistem rujukan maternal yang hasilnya puskesmas melaksanakan prosedur klinis dengan melakukan stabilisasi pasien rujukan dan merujuk ke sarana kesehatan yang lebih mampu jika Puskesmas tidak mampu serta memonitoring dan evaluasi kemajuan klinis pasien.

Pada Hasil penelitian didapatkan bahwa cara pembayaran kasus kegawatdaruratan yang banyak dipakai adalah dengan menggunkan BPJS sebanyak 57 kasus, sedangkan pada kasus lainnya menggunakan cara pembayaran dengan Jamkesmas dan Umum atau tidak menggunakan asuransi kesehatan.

\section{KESIMPULAN}

Kasus Kegawatdaruratan Maternal yang terjadi di Puskesmas PONED Tanjungsari pada tahun 2015 adalah Perdarahan Trimester 1, Perdarahan Trimester 2, Ketuban Pecah Dini, Hipertensi, Kelainan letak janin dan kasus terbanyak adalah Ketuban Pecah Dini. Umur maternal yang mengalami kasus kegawatdaruratan terbanyak berkisar antara 20-35 tahun. Status Paritas maternal yang mengalami kasus kegawatdaruratan terbanyak adalah 2-3. Tidak terdapat kasus rujukan Neonatal di puskesmas PONED Tanjungsari pada tahun 2015. Luaran kasus kegatdaruratan maternal yang dirujuk ke RS PONEK sebagaian besar adalah sehat, dan pembayaran rujukan berdasarkan biaya terbanyak menggunakan BPJS.

\section{DAFTAR PUSTAKA}

BppdK Sumedang., 2014. Profil daerah Kabupaten Sumedang 2014. Sumedang: Badan Perencanaan Pembangunan Daerah Kabupaten Sumedang (BppdK).

Kementrian Kesehatan RI., 2012. Pedoman penyelenggara PONEK 24 jam di rumah sakit. Jakarta : Kementrian Kesehatan RI. pp. 4,65 .

Kementrian Kesehatan RI., 2013. Pedoman PONED. Jakarta: Kementrian Kesehatan RI. 
Kementrian kesehatan RI., 2014. Situasi kesehatan ibu. Jakarta: Pusat data dan informasi kementrian kesehatan RI.

Lawn JE, Davidge R, Paul VK, Xylander SV, Johnson JG, Costello A., 2013. Born too soon : care for the preterm baby. Reproductive Health Journal 2013; 10:119.

Manuaba, I.B.et al., 2004. Kepaniteraan Klinik Obstetri dan Ginekologi. Jakarta : EGC

Natiqotul, Fatkhiyah., 2008. Hubungan status paritas dengan kejadian persalinan ketuban pecah dini di RSUD dr. Soeselo Slawi Kabupaten Tegal Tahun 2008. STIKES BHAMADA-Slawi.

Nurul, Huda., 2013. Faktor-faktor yang Mempengaruhi Ketuban Pecah Dini di RS
PKU Muhammadiyah Surakarta. Universitas Muhammadiyah Surakarta.

Rizki, T.M ., 2012. Hubungan karakteristik ibu hamil dengan kejadian komplikasi persalinan di RS PKU Muhammadiyah Yogyakarta Tahun 2012. STIKES AISYIYAH.

Rukmini, R ., Pelaksanaan sistem rujukan maternal di puskesmas Tambakrejo dan Tanah Kali Kedinding Kota Surabaya. Badan Litbang Kesehatan Surabaya.

Sarifudin AB, George A, Wiknjosasatro GH, Waspodo D., 2009. Buku acuan nasional pelayanan kesehatan maternal dan neonatal ed.1. Jakarta : PT Bina pustaka Sarwono Prawihardjo..p. 145-72. 